\title{
O CURRICULO E O LIVRO DIDÁTICO DO BRASIL E DA ESPANHA. UM CASO: O INDÍGENA DA AMÉRICA HISPÂNICA
}

\author{
Léia Adriana da Silva SANTIAGO ${ }^{1}$ \\ Joan Pagès BLANCH ${ }^{2}$
}

Resumo: Este artigo analisa a temática indígena no currículo de história e nos manuais didáticos do ensino fundamental no Brasil e do secundário na Espanha, quando se referem a América Latina. A questão que se coloca é perceber quais são os conteúdos incluídos nas duas propostas e os que estão presentes em quatro livros didáticos selecionados, a fim de verificar se tem sido estimulada a formação de uma consciência histórica e cidadã. Também examinamos os símbolos e significados dados aos conteúdos sobre a América Latina, que são selecionados para transmitir ao aluno. $\mathrm{O}$ texto está dividido em três partes. Na primeira estão dispostos os dados referentes à temática indígena da América Hispânica nas propostas curriculares do Brasil e da Espanha. $\mathrm{Na}$ segunda e na terceira parte, analisamos os conteúdos sobre os povos autóctones hispano-americanos, presentes nos quatro livros didáticos selecionados. Finalmente, concluímos que ainda é necessário um longo percurso para que seja possível ressignificar um ensino de história que estimule uma consciência histórica e cidadã, pois há uma história que silenciosamente mantém conteúdos, ideias e representações preconceituosas no tratamento da temática indígena.

Palavras-chave: Temática indígena. Ensino de Historia de América. Currículo. Livros didáticos.

\section{Introdução}

Neste artigo, propomos refletir o que tem sido veiculado nas propostas curriculares do Brasil e da Espanha e nos livros didáticos de história acerca da temática indígena, e se esses conteúdos têm contribuído para a formação de uma consciência histórica e cidadã, uma vez que, a conciencia histórica é “[...] a suma das operações mentais com as quais os homens interpretam sua experiência da evolução temporal de seu mundo e de si mesmos, de forma tal que possam orientar, intencionalmente, sua vida prática no tempo.” (RÜSEN, 2001, p. 51)

1 IF - Instituto Federal Goiano, Câmpus Morrinhos. Morrinhos - GO - Brasil. 76200-000 leia.adriana@ifgoiano.edu.br

${ }^{2}$ UAB - Universitat Autònoma de Barcelona. Facultat de Ciències de l'Educació - Departament de Didàctica de la Llengua, de la Literatura i de les Ciències Socials. Responsável pelo Grupo de Investigação em Didática das Ciências Sociais (GREDICS). Barcelona - Espanha. 08193 joan.pages@uab.cat 
Assim, este artigo traz na primeira parte o que tem sido veiculado sobre a América Latina nas propostas curriculares do Brasil e da Espanha, observando o que tem sido proposto sobre a temática indígena da América Hispânica.

$\mathrm{Na}$ segunda e terceira parte, analisaremos os conteúdos referentes à temática indígena da América Hispânica contidos em dois manuais didáticos de História, usados nos anos finais do ensino fundamental no Brasil (APOLINÁRIO, 2007; BOULOS, 2012) e dois manuais didáticos de História e Ciências Sociais do ensino secundário na Espanha (GONZALES; PABÓN, 2008; LOPÉZ; IZQUIERDO, 2012).

\section{A temática indígena da América Hispânica nas propostas curriculares do Brasil e da Espanha}

O tema da América Latina tem sido veiculado nas propostas curriculares da Educação Básica, no Brasil, desde a segunda metade do século XIX. A América esteve integrada aos estudos da História Universal e da História do Brasil e temas como o "descobrimento" da América, os conflitos na região do Prata, os processos de independência e a Guerra do Paraguai estiveram presentes em quase todos os currículos.

É a partir da proposta curricular de 1931, que os povos indígenas da América Hispânica começam a aparecer como conteúdo de estudo na história escolar. Em todas as propostas que seguiram, nos anos de 1942, 1951 e 1971 permaneceu o tema, caracterizado pelo estudo dos incas, maias e astecas ou principais povos précolombianos.

A última proposta curricular promulgada em 1996, denominada de Parâmetros Curriculares Nacionais (PNCs), foi fruto de mudanças políticas e sociais que aconteceu no Brasil, pelo processo de redemocratização. As diretrizes das políticas públicas deste período se voltaram para a cultura e a educação, incorporando metas de conservação e recuperação do patrimônio nacional das memórias múltiplas, reconhecendo as diferentes identidades (ZAMBONI, 2003).

Nesse sentido, os PCNs colocam que ensino da História escolar deve favorecer a construção, pelo aluno, de noções de diferença, semelhança, transformação e permanência, para auxiliar na identificação e na distinção do "eu", do "outro" e do "nós". Entretanto, o fato de ampliar as visões do "eu", do "outro" e do "nós" não significou mudanças no olhar sobre a identidade indígena hispano-americana. Os indígenas de toda a América Hispânica permanecem tratados no passado e sendo 
qualificados genericamente, como incas, maias e astecas, tornando invisível a existência de muitos outros povos e culturas distintas a estes.

Como no Brasil, a América Latina também está presente nos currículos da Espanha desde o século XIX, com os temas do descobrimento e dos processos de independência.

Assim, por exemplo, no Real Decreto 1007/1991 que estabelecia os conteúdos mínimos correspondentes a Educação Secundária Obrigatória, existia entre os temas estudados, a "colonização da América e o impacto recíproco", as guerras de independência e o estudo das "Sociedades e culturas diversas" do período contemporâneo.

Na lei de educação de 2006, aprovada pelo partido socialista ${ }^{3}$, sobre a América Latina figura explicitamente os conteúdos referente à colonização e as guerras de independência da América espanhola. Embora não seja possível identificar o estudo das populações indígenas da América, cabe destacar que entre os objetivos prescritos no Real Decreto 1631/2006 está:

5. Identificar y localizar en el tiempo y en el espacio los procesos y acontecimientos históricos relevantes de la historia del mundo, de Europa y de España para adquirir una perspectiva global de la evolución de la Humanidad y elaborar una interpretación de la misma que facilite la comprensión de la pluralidad de comunidades sociales a las que se pertenece.

6. Valorar la diversidad cultural manifestando actitudes de respeto y tolerancia hacia otras culturas y hacia opiniones que no coinciden con las propias, sin renunciar por ello a un juicio sobre ellas. (ESPAÑA, 2007, p. 28).

Finalmente na última lei de educação aprovada em 2013, pelo governo do Partido Popular $^{4}$ - a Ley Orgánica para la mejora de la calidad educativa (LOMCE), os conteúdos da conquista, colonização e independências estão propostos para a disciplina

${ }^{3}$ A LOE - Ley Orgánica de Educación - foi aprovada em 3 de maio de 2006 pelo Congresso dos Deputados a proposto do Partido Socialista Obreiro Espanhol, dirigido por José Luís Rodríguez Zapatero. Esta lei substituiu a LOGSE, outra lei de educação aprovada também pelo Partido Socialista em 1990 (ESPAÑA, 2006, 2013).

${ }^{4}$ A LOMCE, conhecida também como Ley Wert, nome do ministro que a redigiu, foi aprovada em 28 de novembro de 2013, com os votos do Partido Popular, dirigido por Mariano Rajoy e a oposição dos demais grupos políticos do Congresso de Deputados e a contestação da maioria dos setores sociais e políticos da Espanha. 
de história do ensino secundário obrigatório ${ }^{5}$. Entre os padrões avaliativos de aprendizagem, expostos na lei, há um que parece apostar por favorecer interpretações distintas da conquista e da colonização: "Sopesa interpretaciones conflictivas sobre la conquista y colonización de América" (ESPAÑA, 2015, p. 300). Entretanto, ainda não é possível avaliar o desenvolvimento desta, pois a mesma foi posta recentemente em funcionamento.

Frente ao exposto nos parágrafos acima sobre as propostas curriculares do Brasil e da Espanha, voltamos o nosso olhar para os livros didáticos, porque são o suporte básico e sistematizador privilegiado dos conteúdos prescritos no currículo (BITTENCOURT, 1998) e tem sido um dos componentes da cultura escolar, nos dois países, desde que estes promulgaram as primeiras propostas e leis de educação.

\section{A temática indígena da América Hispânica nos livros didáticos do Brasil}

O livro didático escrito pela editora Moderna e organizado por Apolinário (2007), intitulado Projeto Araribá História para do sétimo ano do ensino fundamental, é o que contêm o estudo dos povos indígenas da América hispânica. Dentro da unidade cinco, que tem como tema "O Encontro entre dois mundos", há três capítulos dedicados ao estudo da chegada dos europeus na América e posteriormente, outros três capítulos dos povos indígenas. É interessante observar que esta forma como o livro dispõe os capítulos dentro da unidade, permite que se crie a imagem de que o tema esteja vinculado ao estudo da história europeia.

No capítulo quatro, contendo somente duas páginas, esta a imagem (Ilustração 1) de um mapa e um esquema mostrando onde se localizam as civilizações que habitavam a América. Todavia, embora o mapa e o esquema apresentem várias civilizações, a autora descreve que serão estudadas somente as civilizações asteca, inca e maia.

\footnotetext{
${ }^{5}$ O Ensino secundário obrigatório ou Enseñanza Secundaria Obligatoria (ESO), faz parte do sistema educativo espanhol obrigatório, que vai dos 6 aos 16 anos, sendo que os quatro últimos anos compõe a ESO.
} 
Ilustração 1 - Mapa e esquema dos povos americanos Projeto Araribá História, destinado ao $7^{\circ}$ ano.
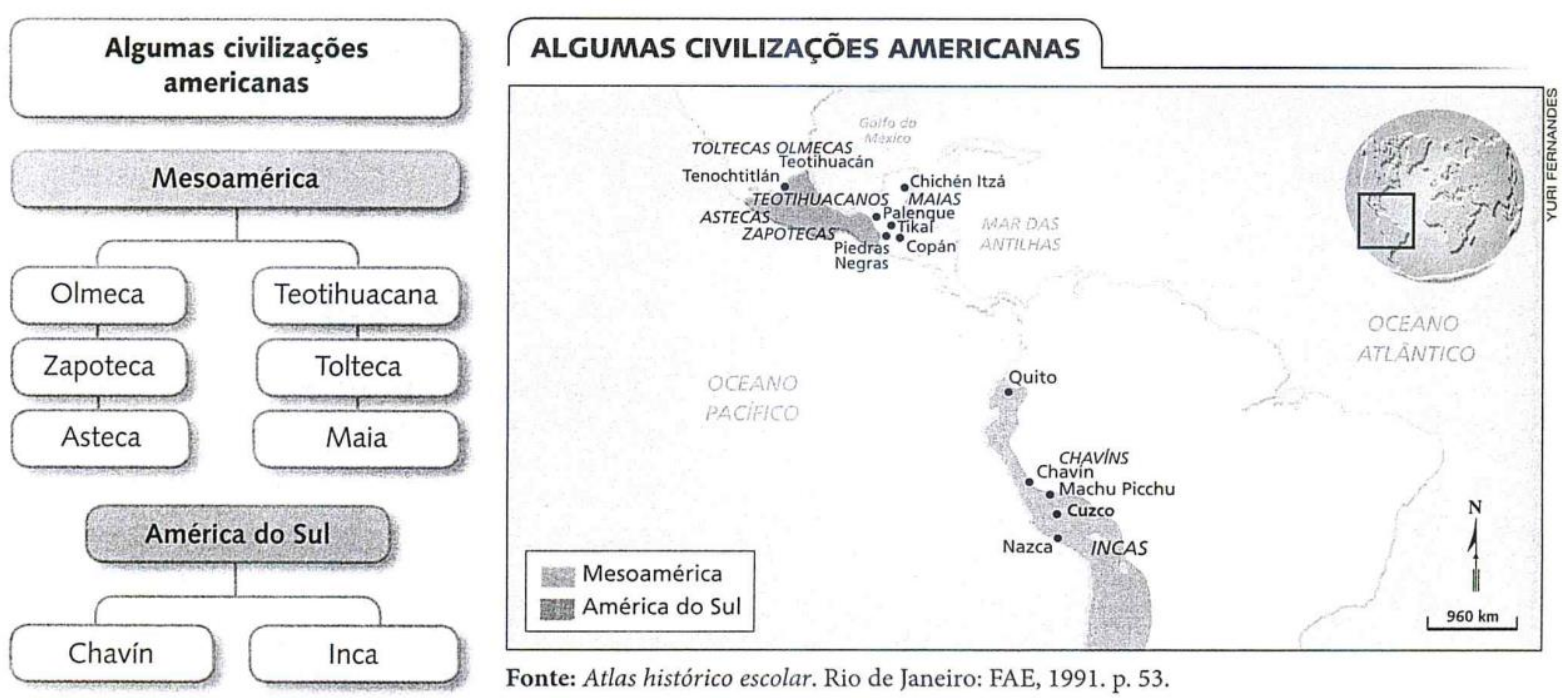

Fonte: (APOLINÁRIO, 2007, p. 142).

O capítulo cinco inicia com o tema da civilização asteca. Três páginas são dedicadas ela, tendo como subtemas a formação do império; as atividades econômicas; a educação dos meninos e das meninas; a religião e a arte e o calendário asteca.

Sobre a formação do império asteca o texto traz que a fundação da cidade de Tenochtitlán ocorreu em 1325 e a partir desta cidade, foram conquistados cidades e povos vizinhos da região.

Da economia asteca a autora descreve que havia o cultivo do milho, feijão, pimenta, abóbora, cacau, algodão, tabaco, frutas e verduras. Domesticaram animais como perus, cachorros e patos e também tinham a caça e a pesca para a sobrevivência. O texto ainda destaca a importância do artesanato em cerâmica, pedras e metais desenvolvido pelos astecas.

Em seguida a autora trata do tema da educação dos meninos e das meninas. Segundo ela, quando pequenos, os meninos aprendiam a carregar água, madeira, pescar, dirigir barcos e acompanhavam o pai no mercado. Coube aqui observar que o mercado não foi citado pela autora, dentro do subtema da economia asteca, embora ele tenha sido muito importante para esta civilização, pois ali eram vendidos artigos de ouro e prata, adornos, carnes, alimentos e escravos (MEGGERS, 1979).

Na continuidade a autora expõe que aos 15 anos os meninos podiam entrar em dois centros de ensino: o calmecac e o telpochcalli. O calmecac visava formar sacerdotes e altos funcionários de Estado e o telpochcalli visava à formação para o 
trabalho no comercio e em funções menos privilegiadas do Estado. As meninas aprendiam com as mães a tear, as tarefas de casa e a moer o milho.

Crosher (1988) tratando a respeito da civilização asteca descreve que as crianças frequentavam a escola até completarem oito anos, para aprenderem o básico da escrita e as tradições astecas, a partir de então, os meninos passavam a acompanhar o pai nas suas atividades e a menina ficava com a mãe aprendendo as atividades domésticas. Apesar de o texto didático identificar corretamente a divisão da educação entre os meninos e as meninas, ele não se deteve a retratar o fato de que dentro desta educação havia um momento em que os meninos e meninas permaneciam juntos, para aprenderem algo que lhes era comum, dentro da sociedade.

Da civilização inca a autora narra, no capítulo seis, a respeito da dominação política, das atividades econômicas, da composição das elites incaicas, da cidade de Machu Pichu e da astromonia inca. Todo o texto está retratado dentro do passado histórico dos incas. Não há qualquer alusão ao legado deixado pelos incas ou informações sobre descendentes atuais desta nação.

Fato a ser observado no tema, "a composição das elites incaicas", é que este descreve todas as etapas de vida do imperador, desde o seu nascimento até a morte. Junto a este texto há uma imagem (Ilustração 2) sobre o trabalho com as lhanas na região dos Andes, na atualidade. Ao lado da imagem há uma pequena tarja com a identificação do que ela representa.

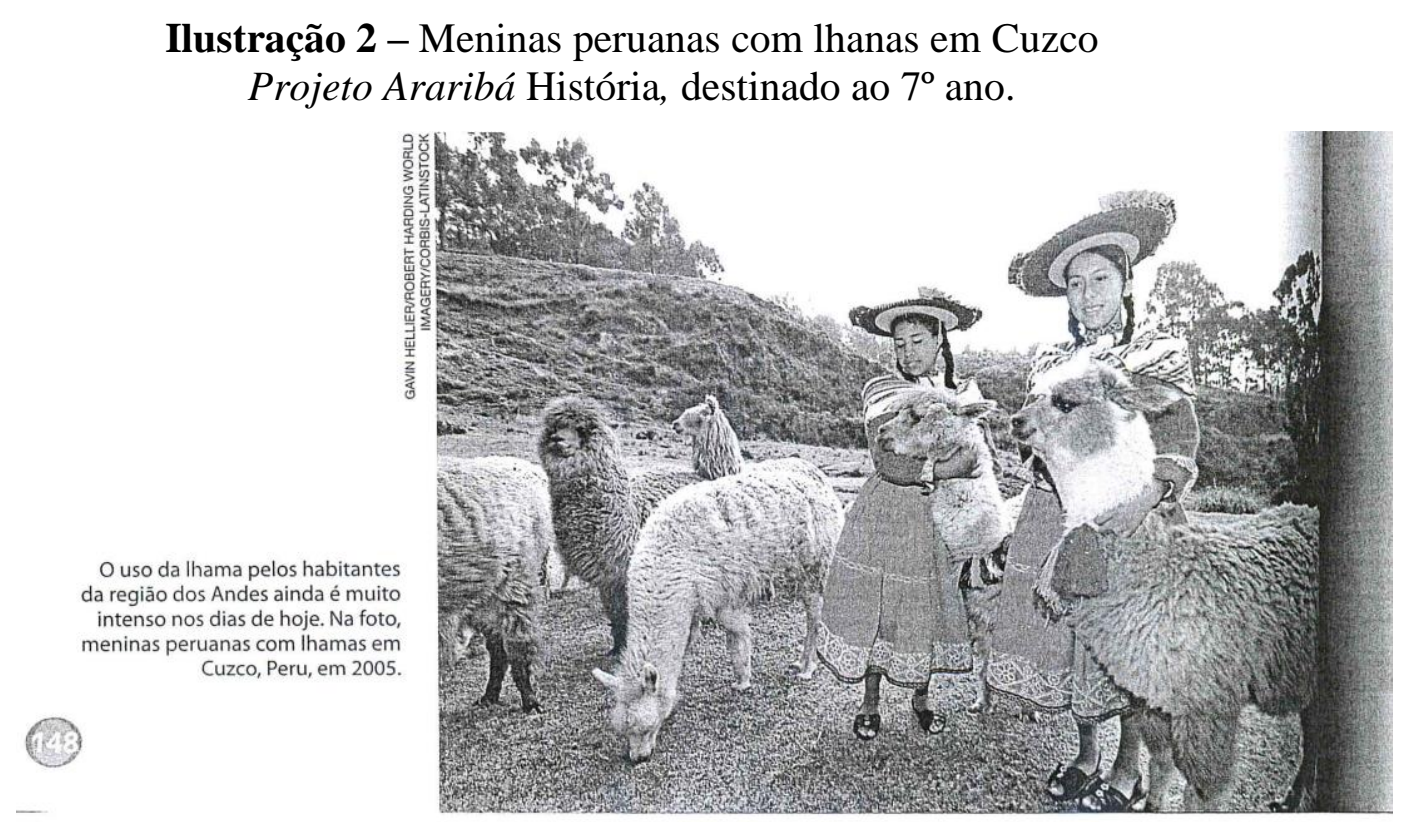

Fonte: (APOLINÁRIO, 2007, p. 148). 
A autora não faz uma articulação entre a imagem e o texto e também não traz uma referência de que esta forma de trabalho se constitui um legado dos tipos de trabalho exercidos pelos incas no passado, uma vez que o pastoreio e a domesticação da llana e da alpaca, foi uma das suas principais atividades econômicas. A alpaca fornecia a lã para tecelagem, enquanto a lhama servia como besta de carga. Suas carnes eram transformadas em charki (carne seca ao sol), as peles utilizadas na confecção de roupas, os ossos empregados na fabricação de utensílios (agulhas), e seus excrementos substituíam a madeira como combustível (FAVRE, 1998).

Sobre os maias o texto, intitulado "A enigmática civilização maia", contido ainda no capítulo seis, inicia dizendo que a civilização desenvolveu-se na área que corresponde ao sul do atual México, da Guatemala, Belize e Honduras. Na continuidade a autora descreve que a história dos maias é dividida em três períodos denominados préclássico (1000 a.C. a 250 d.C.), clássico (250 a 900) e pós-clássico.

O texto prossegue apresentando subtemas que, necessariamente não seguem a divisão dos períodos informados na introdução. Estes são divididos em três, tendo como títulos, chefes políticos e religiosos; uma civilização agrícola e os senhores do tempo.

Os três subtemas estão trazendo o passado da civilização maia, mas a autora a respeito desta civilização expõe um legado deixado por ela. Está incluída no capítulo, uma página onde é citado o Parque da cidade de Tikal, declarado pela UNESCO como patrimônio da humanidade.

Outro livro didático é o da coleção "Sociedade \& Cidadania História", escrito por Alfredo Boulos. Neste livro, o tema dos povos indígenas da América Hispânica também é veiculado no sétimo ano, na unidade intitulada "Nós e os Outros", que trata das grandes navegações europeias, dos povos astecas, maias e incas e dos Tupi no Brasil. Assim como o livro organizado por Apolinário (2007), a disposição dos capítulos dentro da unidade, também permite construir a representação da existência de uma América, que tem sua história vinculada a dos europeus.

É no capítulo onze que estão os conteúdos referentes aos astecas, maias e incas. O texto começa indicando as fontes que são utilizadas para o estudo da história americana e na sequencia descreve que havia uma diversidade de povos indígenas habitando a América, antes da chegada dos europeus, mas o capítulo se deteria ao estudo de três deles: os astecas, os maias e os incas. 
Observando o que está exposto neste livro e no organizado por Apolinário (2007), vemos que sobre a América Hispânica, na história escolar brasileira, há mais permanências do que mudanças. Os dois livros estão contidos no último guia didático, do programa nacional do livro didático ${ }^{6}$, como textos recomendados para serem utilizados até 2017, nas escolas públicas por todo o país e eles ainda têm mantido somente o estudo dos maias, incas e astecas, como vem ocorrendo desde a década de 1930, nas escolas brasileiras.

Os astecas estão descritos no texto, em subtemas que tratam da chegada destes na região central da América, da formação do império, da cidade de Tenochtitlán, da sociedade asteca e do esporte e da saúde.

O tema do esporte e da saúde não se encontra descrito no livro analisado anteriormente. Sobre a questão da saúde o autor descreve que os astecas utilizavam a flora e a fauna para fazer remédios à base de gordura animal e plantas medicinais e prossegue sinalizando que as causas das doenças eram atribuídas aos deuses e aos feitiços, por isto, os astecas utilizavam as orações e as adivinhações para a cura destas. Nosella (1979) ressalta que tem sido comum e tem permanecido nos livros didáticos, a descrição dos índios como "supersticiosos", "selvagens", "bárbaros”, em estágio de civilização mais atrasado, demonstrando assim, a inferioridade de sua cultura.

Da civilização maia o autor traz no capitulo a sua formação política, a sociedade e a economia e a astronomia. Os subtemas citam informações sobre as cidades maias classificando-as como pequenos estados independentes; as pirâmides como templos religiosos; a sociedade formada por nobres, sacerdotes, artesãos e agricultores; a agricultura como base da economia - sendo o milho o principal produto e sobre a astronomia, a elaboração dos calendários.

Dos maias a narrativa exposta pelo autor faz referência somente ao seu passado histórico, encerrando com a descrição de que estes, a partir do ano 900 abandonaram suas cidades e se espalharam pela região. O motivo é desconhecido pelos historiadores, havendo a hipótese de esgotamento das terras, epidemia ou chuvas torrenciais e prolongadas.

O autor inicia a descrição dos incas dizendo que de acordo com a mitologia inca, estes tinham origem divina, por isto eram chamados de filhos do sol. Segundo a lenda, o

\footnotetext{
${ }^{6}$ Este programa, pertence ao governo federal brasileiro, que seleciona alguns livros que deverão ser escolhidos pelos professores, para o trabalho na sala de aula. No entanto, este programa não existe na Espanha.
} 
império inca foi fundado por dois personagens lendários, Manco Capác e sua esposa irmã Mama Ocilla. Nos parágrafos que seguem, o autor expõe que hoje já se sabe que por volta de 1400 os incas viviam nas terras altas da cidade de Cuzco e que a partir de 1438 conquistaram a cidade e expandiram o seu território, construindo o maior império indígena da América.

Lopes (1995) tem advertido que no contexto escolar brasileiro os mitos indígenas têm sido frequentemente utilizados como um recurso pedagógico, sendo em algumas situações, transmitidos com correções segundo o que é considerado moralmente e ideologicamente correto. Embora muitas vezes a intenção seja a divulgação da "cultura indígena", a tradição herdada do pensamento ocidental advinda da antiguidade, nos faz ver o "outro" como inferior. Nesse sentido, os mitos utilizados, sem uma compreensão do seu significado para cada sociedade, permitem que esta seja representada num estágio de infância primitivo da humanidade e suas produções, em especial os seus mitos, seja vistos como "coisas de criança", como narrativas próximas aos contos maravilhosos, que estimulam a imaginação.

Dos incas o capítulo ainda trata do tema da cidade de Machu Pichu - que esta permaneceu intacta até 1911, quando foi redescoberta e hoje é visitada por milhares de turistas de todo mundo; da economia e da sociedade; e do Kipu - que registrava tipos e quantidades de produtos armazenados, datas, número de pessoas, animais e armazéns existentes no império.

\section{A temática indígena da América Hispânica nos livros didáticos da Espanha}

Sobre os livros didáticos veiculados na Espanha, o livro escrito por López e Izquierdo (2012), intitulado Història: Secundària, para o $4^{\circ}$ ano da ESO, traz o tema dos maias, incas e astecas na primeira unidade, com o título, "A gêneses do mundo moderno". A unidade trata nos três primeiros capítulos, a respeito dos estados europeus no século XV, da monarquia dos reis católicos e das explorações geográficas, sendo que neste último, está o "descobrimento" da América.

Logo após o conteúdo referente ao "descobrimento" da América, entra o quarto capítulo trazendo o estudo dos incas, maias e astecas, intitulado, "Como era a América Pré-colombiana?". Chama atenção o fato de que o livro, semelhantemente aos livros brasileiros analisados, também insere o tema dentro do contexto da história da europeia, mais especificamente, da história da Espanha. Rodrigues (2005) tem destacado que a 
temática indígena nos livros didáticos vem sendo tratada como uma questão específica, dentro de uma questão genérica. Nesse sentido, ela é apresentada nos manuais, como simples aporte de um conteúdo mais abrangente, como ilustrativas, que permitem a exposição dos povos indígenas de forma generalizada.

O texto exposto no livro de López e Izquierdo (2012) inicia dizendo que antes da chegada dos espanhóis, na América havia culturas, que têm sido chamadas hoje, de Précolombianas. As mais desenvolvidas foram os incas, maias e astecas.

Sobre os três povos, o capítulo expõe, com pequenas exceções, uma sequencia que traz a descrição de quem eles eram, suas principais cidades, a sociedade, a economia e a religião.

A respeito dos incas os autores do texto destacam que era um povo guerreiro, que construíram cidades com grandes fortalezas de pedras; que mantinham uma sociedade hierarquizada e organizada por clãs unidos por parentescos; que cultivavam milho, batata e cuidavam de rebanhos de lhamas e alpacas e que desenvolveram a metalurgia e a cerâmica. Seus principais deuses eram Viracocha, a Lua e o Sol. Os autores ainda destacam que Atahualpa foi o inca que encontrou Pizarro quando ele chegou a estas terras.

Do tema da civilização maia os autores apontam que eles viviam ao sul do México e Guatemala e estavam organizados em cidades-estados governadas por um chefe militar supremo. A sociedade era composta por nobres, agricultores e escravos cativos de guerra. Dedicavam-se ao cultivo do milho, ao artesanato, cestaria e praticavam o comércio com seus vizinhos. Desenvolveram a matemática e tinham amplos conhecimentos astronômicos. Seus principais deuses foram Cac, deus da chuva, Centéotl, deus do milho e Cuculcán, deus do vento. Em honra a estes deuses praticavam sacrifícios, danças rituais e jogos.

No outro texto do livro, que relata a respeito dos astecas, este se inicia com a descrição de que era um povo guerreiro, que tinha como principais cidades Tenochtitlán, Texcoco e Tlacopan. Sua sociedade era formada por sacerdotes, nobres, homens livres e escravos de guerra que não haviam sido sacrificados aos deuses. Sua economia era baseada no cultivo do milho, no pagamento de tributos, na cerâmica e na pintura de tecidos. Seus principais deuses eram Quetzacoatl, deus criador da terra e das pessoas e Huitzilopochtli, deus da guerra - a ele se oferecia os sacrifícios humanos.

O texto encerra dizendo que quando os espanhóis entraram em contato com os astecas, este império era governado por Montezuma II (1502-1520). 
Os três textos exibidos no livro López e Izquierdo (2012) apresentam semelhanças com o que foi proposto pelos dois livros brasileiros, porque todos eles trouxeram os temas da sociedade, economia e religião em suas descrições se basearam no passado destas civilizações.

Entretanto, notamos que o livro de López e Izquierdo (2012) retrata de modo bastante simplificado, a realidade vivenciada pelas três sociedades indígenas. Também pudemos observar que diferente dos livros brasileiros, López e Izquierdo (2012) caracterizaram, nos textos, que os maias, incas e astecas eram povos guerreiros.

Seria possível pensar que os autores, ao caracterizar estes povos como guerreiros, também estariam alimentando o imaginário de que os espanhóis venceram estes povos e dominaram os seus territórios por aproximadamente três séculos, pois, como observa Chartier (1991) a representação, como dando a ver uma coisa ausente, faz enxergar um objeto que não está presente, através de sua substituição por uma imagem que seja capaz de reconstituir este objeto em memória.

Ainda no livro de López e Izquierdo (2012), há uma página com duas imagens representando os povos pré-colombianos. A primeira imagem traz a Pirâmide do Sol, da cidade de Teotihuacán, no México. A segunda imagem (ilustração 3) expõe peças précolombianas, que parecem ser produzidos em metal, mas não traz qualquer identificação da civilização que as fez. Sabe-se, conforme descreve Crosher (1988) e Favre (1998), que tanto os astecas como os incas desenvolverem a arte da ourivesaria. Os artesãos confeccionavam peças e ornamentos como braceletes, peitorais, tiaras e joias, em ouro e pedras preciosas. Já os maias conheciam o processo técnico do uso do metal, porém o utilizavam somente em adornos, por causa de sua escassez na região. Entre os maias predominou o trabalho com uma pedra ornamental denominada jade, que era comumente encontrada na região onde habitavam ${ }^{7}$.

Ilustração 3 - Peças Pré-colombianas. Història - Secundària $4^{\circ}$ t ESO.

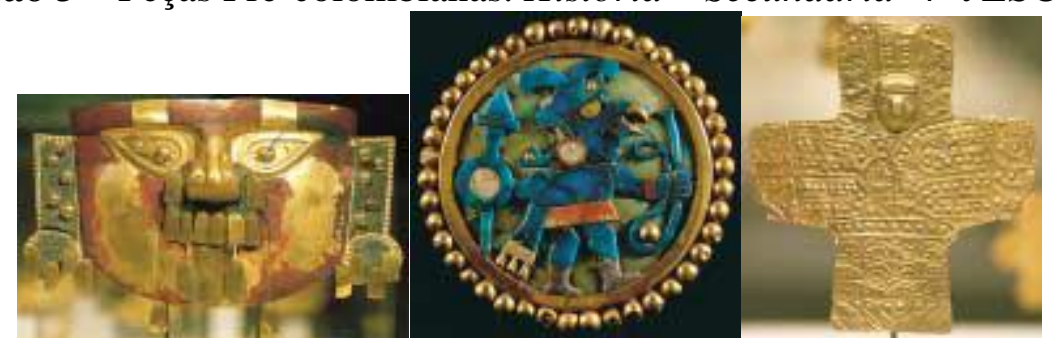

DOC. 2. Peces precolombines

Fonte: (LOPÉZ; IZQUIERDO, 2012, p. 17).

${ }^{7}$ Dados retirados do site: <http://www.mayasautenticos.com/arte_maya.htm>. Acesso em: 16/12/2015. 
Outro livro didático espanhol analisado foi escrito por González e Pabón (2008), tendo como título, Ciencias sociales: geografía e historia. Ele é destinado aos alunos que necessitam obter o título de graduado em educação secundária e apresenta na unidade doze, o conteúdo referente aos povos americanos. A unidade tem como título "Los grandes descubrimientos geográficos", e é no capítulo quatro, dentro do tema "conquista e colonização da América" que eles estão postos.

As autoras iniciam o texto relatando que ao final do século $\mathrm{XV}$, os espanhóis chegaram à América e encontraram o território habitado por povos - conhecidos hoje, como ameríndios - que se encontrava em um período evolutivo similar ao neolítico.

Podemos dizer que as autoras iniciaram o texto representando os povos americanos, como povos atrasados, em estágio inferior de civilização. Além desta representação, também é possível dizer que elas os classificaram genericamente, ou seja, como se formassem um todo homogêneo, ao coloca-los dentro de um mesmo período evolutivo. Grupioni (1995) tem apontado que os manuais escolares continuam a ignorar as pesquisas feitas pela História e pela Antropologia no conhecimento do "outro", revelando-se deficientes no tratamento da diversidade étnica e cultural existentes desde os tempos da colonização aos dias atuais.

$\mathrm{Na}$ continuidade, as autoras relatam que no momento do descobrimento se desenvolviam na América três culturas fundamentais: astecas no México, maias em Yucatán e América Central e incas na zona andina da América do Sul.

Elas descrevem que embora fossem culturas diferentes e autônomas, apresentavam algumas características comuns: viviam da agricultura, principalmente do cultivo do milho, não conheciam a escrita e nem a roda, não possuíam animais de tração e utilizavam o ouro e a prata para confecção de objetos de adorno.

$\mathrm{Na}$ sequencia as autoras tratam de cada uma destas civilizações falando da formação e organização política, da sociedade, da religião e da economia, assim como os demais livros apresentados neste artigo.

Embora haja diferenças na forma de escrita do livro de López e Izquierdo (2012), os dois - com quatro anos que separam suas publicações - veiculam o mesmo conteúdo sobre as civilizações inca, maia e asteca, apresentando um relato sobre o passado destes povos, sem nenhuma alusão ao legado cultural deixado por estes e à história dos seus descendentes nos dias atuais. 
Rodrigues (2005) avaliando a temática indígena nos livros didáticos brasileiros observa que a "visão de índio" que é ensinada permanece a mesma de anos atrás; que os povos indígenas não fazem parte da história atual e que a imagem das sociedades indígenas comuns ao público em geral continua sendo estática, vivendo em aldeias, representando um passado remoto, uma etapa evolutiva do homo-sapiens. Embora as representações indicadas por Rodrigues (2005) estejam presentes na história escolar brasileira cremos, diante do exposto acima, que seja possível sinalizar que elas também estejam presentes no ensino de história escolar que é veiculado na Espanha.

\section{Considerações finais}

Mediante as constatações levantadas neste artigo, percebemos que os livros didáticos ainda necessitam de um longo percurso para que seja possível ressignificar um ensino de história e ciências sociais que estimule uma consciência histórica e cidadã. Ainda há uma história que silenciosamente mantém conteúdos, ideias e representações preconceituosas no tratamento da temática indígena.

Daí a necessidade de que os resultados da pesquisa histórica sejam didaticamente transpostos para as carências de orientação que os tornam necessários, como também é necessário que haja uma superação do abismo existente entre o conhecimento adquirido pelos especialistas sobre as sociedades indígenas e o que é veiculado na cultura escolar, a fim de que seja possível conciliar os direitos de igualdade dos cidadãos e os direitos à diferença de culturas, evitando que posturas discriminatórias possam ser alimentadas (REIS, 1999).

Para tanto, faz-se necessário continuar a aperfeiçoar a análise das políticas públicas, das propostas curriculares e leis de educação, dos materiais didáticos e dos saberes e práticas dos professores, para que se tenha uma visão de futuro que passe por um ensino de história e de ciências sociais dirigidos à formação democrática de alunos e alunas que poderão utilizar os conhecimentos históricos e sociais

[...] para interpretar y participar en su mundo como ciudadano crítico, con opinión propia, y con clara conciencia de que el futuro le deparará muchos cambios. Y uno de estos cambios será, sin duda, el de la existencia de una realidad cada vez más global, diversa y plural. (PAGÈS, 2001, p. 285) 


\title{
Agradecimentos
}

Agradecemos à Fundação Capes pelo apoio financeiro no desenvolvimento do estágio pós-doutoral, na Universidade Autônoma de Barcelona - Espanha, do qual, este artigo é resultado parcial da pesquisa.

\section{BRAZILIAN AND SPANISH CURRICULUM AND TEXTBOOKS - A CASE: THE INDIGENOUS OF HISPANIC AMERICA}

\begin{abstract}
This paper analyses the indigenous theme on the history curriculum and on the didactic manuals of primary education in Brazil and secondary education in Spain regarding Latin America. The question that guides this work is: which contents are included in both proposals and which ones are presented in four selected textbooks? The aim is to verify whether historical and citizen awareness have been stimulated to be formed. We also examined the symbols and the meanings attributed to Latin American contents, which were selected to be taught to students. This paper is divided into three parts. The first one shows the data about the indigenous theme in Hispanic America in both Brazilian and Spanish curriculum proposals. In the second and in the third parts, we analyze the contents of the autochthone Hispanic Americans presented in four selected textbooks. Finally, we conclude that it is still necessary a long way to give a new possible meaning to the history teaching that stimulates historical and citizen awareness, since there is a silent history that maintains prejudiced contents, concepts and representations when it comes to indigenous themes.
\end{abstract}

Key words: Indigenous theme. Teaching of History of America. Curriculum. Textbooks.

\section{REFERÊNCIAS}

APOLINÁRIO, M. R. (Org.). Projeto Araribá: História $7^{\circ}$ ano. 2.ed. São Paulo: Moderna, 2007.

BITTENCOURT FERNANDES, C. M. Livros didáticos entre textos e imagens. In: BITTENCOURT FERNANDES, C. M. (Org.). O saber histórico na sala de aula. São Paulo: Contexto, 1998. p. 69-90.

BOULOS, A. J. Sociedade \& cidadania: História $7^{\circ}$ ano. 2. ed. São Paulo: FTD, 2012.

CHARTIER, R. O mundo como representação. Estudos Avançados, São Paulo, v. 5, n.11, p. 173-191, 1991

CROSHER, J. Os Astecas. 4.ed. São Paulo: Melhoramentos, 1988.

ESPAÑA. Real decreto 1105/2014, de 26 de diciembre, por el que se establece el currículo básico de la educación secundaria obligatoria y del bachillerato. Boletín Oficial del Estado, Madrid, 3 enero 2015. Seção 1, p. 169. Disponível em: 
<http://www.boe.es/boe/dias/2015/01/03/pdfs/BOE-A-2015-37.pdf>. Acesso em: 29 jun. 2016.

ESPAÑA. Ley orgánica 8/2013, de 9 de diciembre, para la mejora de la calidad educativa. Boletín Oficial del Estado, Madrid, 10 dic. 2013. Disponível em:

<http://www.boe.es/diario_boe/txt.php?id=BOE-A-2013-12886>. Acesso em: 26 out. 2015.

ESPAÑA. Real decreto 1631/2006, de 29 de diciembre, por el que se establecen las enseñanzas mínimas correspondientes a la Educación Secundaria Obligatoria. Boletín Oficial del Estado, Madrid, 5 enero 2007. Seção 1, p. 677. Disponível em: <http://www.boe.es/boe/dias/2007/01/05/pdfs/A00677-00773.pdf>_Acesso em: 29 jun. 2016.

ESPAÑA. Ley Orgánica 2/2006, de 3 de mayo, de Educación. Boletín Oficial del Estado, Madrid, 4 mayo 2006. Disponível em:

<https://www.boe.es/buscar/doc.php?id=BOE-A-2006-7899>. Acesso em: 26 out. 2015.

ESPAÑA. Real Decreto 1007/1991, de 14 de junio, por el que se establecen las enseñanzas mínimas correspondientes a la Educación Secundaria Obligatoria. Boletín Oficial del Estado, Madrid, 14 junio 1991. p.35-77. Disponível em: <http://www.boe.es/boe/dias/1991/06/26/pdfs/C00035-00077.pdf>. Acesso em: 16 nov. 2015.

FAVRE, H. A civilização Inca. 2.ed. Rio de Janeiro: Zahar, 1998.

GONZÁLEZ, E. M. V.; PABÓN, C. F. Ciencias sociales: geografía e historia: grado medio. Sevilla: Editorial MD, S.L., 2008.

GRUPIONI, L. D. B. Livros didáticos e fontes de informações sobre as sociedades indígenas no Brasil. In: SILVA, A. L; GRUPIONI, L. D. B. A temática Indígena na Escola. Brasília: MEC, 1995. p. 481-526.

LÓPEZ, M. A. C.; IZQUIERDO, S. B. Història: Secundària $4^{\circ}$ t ESO. España: Grup Promotor Santillana, 2012.

MEGGERS, B. América pré-histórica. 2.ed. Rio de Janeiro: Paz e Terra, 1979.

NOSELLA, M. L. C. D. As belas mentiras: a ideologia subjacente aos textos didáticos. São Paulo: Cortez \& Moraes, 1979.

PAGÈS BLANCH, J. ¿Hacia dónde va la enseñanza de la Historia y de las Ciencias sociales? apuntes para la comprensión de un debate. ÉNDOXA: Series Filosóficas, Madrid, v. 6, n.14 p. 261-288, 2001.

REIS, M. J. O ensino de História e a construção da identidade nacional: uma união legítima? Interfaces do Ensino de História, Perspectiva, Florianópolis, n. esp., p.99$110,1999$. 
RODRIGUES, I. C. A temática indígena nos livros de história do Brasil para o ensino fundamental. In: ARIAS NETO, J. M. Dez anos de pesquisas em ensino de história. Londrina: AtritoArt, 2005. p. 287-296.

RÜSEN, J. Razão histórica. Brasília: Ed. da UNB, 2001.

ZAMBONI, E. Projeto pedagógico dos parâmetros curriculares nacionais: identidade nacional e consciência histórica. Cadernos Cedes, Campinas, v. 23, n. 61, p. 367-377. 2003. 